\title{
Monitoring of atmospheric radionuclides from the Fukushima nuclear accident and assessing their impact on Xi'an, China
}

\author{
LIU LongBo ${ }^{1 *}$, WU Shan ${ }^{1}$, CAO JunJi ${ }^{2}$, XIE Feng ${ }^{1}$, SHI QuanLin ${ }^{1}$, ZHANG Chang Yun ${ }^{1}$, \\ TANG HanBing ${ }^{1}$, HE XiaoBin ${ }^{1}$, ZHANG Rong ${ }^{2}$, CHEN LiYun ${ }^{1}$, WEI GuanYi ${ }^{1}$, \\ ZHANG ZhiHong ${ }^{1}$, ZHANG JiaMei ${ }^{1} \&$ DANG HaiJun ${ }^{1}$ \\ ${ }^{1}$ Northwest Institute of Nuclear Technology, Xi'an 710024, China; \\ ${ }^{2}$ Institute of Earth Environment, Chinese Academy of Sciences, Xi'an 710075, China
}

Received May 16, 2012; accepted September 4, 2012; published online January 9, 2013

\begin{abstract}
Aerosol radionuclides $\left({ }^{131} \mathrm{I},{ }^{134} \mathrm{Cs},{ }^{137} \mathrm{Cs}\right)$ and gaseous radioactive xenon $\left({ }^{133} \mathrm{Xe}\right)$ were monitored at Xi'an, China following the accident at the Fukushima nuclear power plant in March 2011. The additional annual effective dose attributable to the Fukushima emissions was much lower than the public annual effective dose from natural radiation, according to Chinese national standards. The monitoring results were compared with data from other countries as well as with the radionuclide concentrations observed in $\mathrm{Xi}$ ' an after the Chernobyl nuclear accident in 1986. Possible transport pathways of the released radionuclides from Fukushima to $\mathrm{Xi}$ 'an were investigated. The occurrence of an anticyclone in the Pacific Ocean region and the extended period over which the radionuclides were released made the determination transport pathways complex, but divergence in the plume and easterly flow evidently brought the initial suite of radionuclides to Xi' an.
\end{abstract}

Fukushima nuclear accident, radionuclides, atmospheric radiation monitoring, xenon, transport pathways

Citation: Liu L B, Wu S, Cao J J, et al. Monitoring of atmospheric radionuclides from the Fukushima nuclear accident and assessing their impact on Xi' an, China. Chin Sci Bull, 2013, 58: 1585-1591, doi: 10.1007/s11434-012-5521-4

The Fukushima Daiichi nuclear power plant in Japan was damaged on 11 March 2011 following an earthquake and tsunami, and radionuclides from the power plant were released into the atmosphere for days afterward. Increased concentrations of atmospheric radionuclides characteristic of nuclear power plant emissions, including ${ }^{131} \mathrm{I},{ }^{134} \mathrm{Cs}$ and ${ }^{137} \mathrm{Cs}$, were initially observed at Japanese monitoring stations, then at stations in North America (United States [1] and Canada [2,3]), Europe [4] (Greece [5] and Germany [6]), Asia (Russia [7], China, Korea [8] and Vietnam [9]), and subsequently other countries. Concentrations of ${ }^{131} \mathrm{I}$ higher than background were observed in the above mentioned countries starting on 15 March 2011. The gaseous fission product ${ }^{133} \mathrm{Xe}$, another key radionuclide for moni- toring nuclear accidents, also was measured but only at some locations [10] due to a lack of equipment and facilities. The International Monitoring System (IMS) [11], established by the Comprehensive Nuclear-Test-Ban Treaty Organization (CTBTO), is composed of 63 stations for particulate monitoring and 27 noble gas stations at that time, and at least ${ }^{131} \mathrm{I}$ was detected at all of the IMS stations in the northern hemisphere and three stations in the southern hemisphere within two weeks of the incident ${ }^{1)}$. The concentrations of ${ }^{131}$ I peaked from the end of March to the beginning of April, began to decrease in the middle of April at most of the monitoring stations, and then gradually returned to the background. Meanwhile, Chino et al. [12] and Stohl et al. [13] estimated the quantities of radionuclides released and

\footnotetext{
*Corresponding author (email: lomboliu@live.cn)

1) Stoehlker U, Nikkinen M, Gheddou A. Detection of radionuclides emitted during the Fukushima nuclear accident with the CTBT radionuclide network. 2011 Monitoring Research Review: Ground-Based Nuclear Explosion Monitoring Technologies, 2011.
} 
their release rates with the use of atmospheric transport modeling (ATM) techniques.

On 26 March 2011, the Ministry of Environmental Protection of the People's Republic of China announced for the first time that ${ }^{131} \mathrm{I}$ had been observed during atmospheric monitoring in Heilongjiang Province, but it was also reported that the local environmental radiation level was still in the background range. It was later announced that ${ }^{131} \mathrm{I}$ had been observed in other provinces. Indeed, the environmental radiation levels at all Chinese monitoring stations were in the range of background until May 21 (http://www.mep.gov. cn/gkml/hbb/qt/201105/t20110521_210981.htm). In China, the atmospheric transport of the released radionuclides was analyzed and predictions regarding expected impacts were made by Qiao et al. [14]; and the total quantities of radionuclides released were estimated by Wang et al. [15]. Temporal variations in the concentrations of particulate radionuclides at Beijing and Nanjing were reported by Zhang et al. ${ }^{2)}$ and Zhou et al. [16], respectively. However, to this point, little detailed information has been available on the temporal patterns in the concentrations of either aerosol radionuclides or xenon in China. In the present paper, the monitoring methods for radioactive aerosols and xenon are first summarized; the results are then compared with other monitoring data, and finally, the transport pathways are evaluated.

\section{Methods}

The monitoring program commenced on March 23 at a site in the outskirts of Xi'an, China. The monitoring protocol followed the criteria established for the IMS by the CTBTO $[17,18]$, except for continuance; that is, sampling was conducted continuously but only until April 15. At that point, the sampling frequencies were switched to once per week because the concentrations of radionuclides had decreased dramatically and no further fires or explosions at Fukushima were reported.

\subsection{Particulate monitoring}

Bulk atmospheric aerosol samples were collected with the use of a sampler constructed by the authors [19]; polypropylene fiber filters with collection efficiency of $90 \%$ for 0.2 $\mu \mathrm{m}$ particles [20] were used as the sampling substrates. The sampler operated at a flow rate of $450 \mathrm{~m}^{3} / \mathrm{h}$; the sample volumes were $>10000 \mathrm{~m}^{3}$ of air; and collection intervals were nominally $24 \mathrm{~h}$. The exposed filter media was compacted into a pellet with the use of a hydraulic press. Filter samples were then counted with a high-purity Ge, gamma-ray spectrometer that had a relative efficiency of $60 \%$ and an energy resolution of $1.9 \mathrm{keV}$ at $1.3 \mathrm{MeV}$. The fission- product radionuclides with intermediate half-lives ${ }^{131} \mathrm{I}$, ${ }^{132} \mathrm{Te},{ }^{132} \mathrm{I}$ and ${ }^{137} \mathrm{Cs}$ ) were the analytes of main concern.

The activity of a radionuclide $A$ can be calculated from eq. (1) [21]:

$$
A=\frac{N}{t_{1} \varepsilon_{\mathrm{i}} p_{\mathrm{i}} K_{\mathrm{c}}},
$$

where $N$ is the net peak area; $t_{1}$ is the acquisition live time, $\mathrm{s}$; $\varepsilon_{\mathrm{i}}$ is the attenuation-corrected efficiency at the energy of interest; $p_{\mathrm{i}}$ is the branching ratio of the gamma-ray energy of radionuclide $A$; and $K_{\mathrm{c}}$ is the correction for decay during data acquisition:

$$
K_{\mathrm{c}}=\frac{1-\exp \left(-\lambda t_{\mathrm{m}}\right)}{\lambda t_{\mathrm{m}}},
$$

where $t_{\mathrm{m}}$ is the clock real time from the start to the end of data acquisition, $\mathrm{s}$; and $\lambda$ is decay constant for radionuclide $A, \mathrm{~s}^{-1}$.

The activity concentration of the radionuclide is

$$
C=\frac{A}{V \xi K_{\mathrm{w}} K_{\mathrm{s}}},
$$

where $C$ is the atmospheric concentration of the radionuclide, $\mathrm{Bq} / \mathrm{m}^{3} ; V$ is air volume at standard temperature and pressure $(273.15 \mathrm{~K}$ and $101325 \mathrm{~Pa}), \mathrm{m}^{3}$; $\xi$ is sampling efficiency unit for aerosol sampling; $K_{\mathrm{s}}$ is the correction for radioactive decay during sampling:

$$
K_{\mathrm{s}}=\frac{1-\exp \left(-\lambda t_{\mathrm{s}}\right)}{\lambda t_{\mathrm{s}}},
$$

where $t_{\mathrm{s}}$ is the real time between the start and the end of sampling, s.

$K_{\mathrm{w}}$ is the correction for decay between the end of sampling and the start of data acquisition:

$$
K_{\mathrm{w}}=\exp \left(-\lambda t_{\mathrm{w}}\right),
$$

where $t_{\mathrm{w}}$ is the real time between the end of sampling and the beginning of spectral acquisition, $\mathrm{s}$.

When the activity in samples was less than the MDA (Minimum Detectable Activity), the corresponding activity concentration was regarded as less than MDC (Minimum Detectable Concentration). The MDA can be calculated from eq. (6) [18]

$$
\mathrm{MDA}=\frac{L_{d}}{t_{1} \varepsilon_{\mathrm{i}} p_{\mathrm{i}} K_{\mathrm{c}}}=\frac{2.71+4.65 \sqrt{\mu_{\mathrm{B}}}}{t_{1} \varepsilon_{\mathrm{i}} p_{\mathrm{i}} K_{\mathrm{c}}},
$$

where $\mu_{\mathrm{B}}$ is standard deviation of the background at the region of interest (ROI); $\mu_{\mathrm{B}}=\sum \mathrm{ROI}$; $\mathrm{ROI}$ is defined as $\pm 1.25 \times$ 
full-width half-maximum $( \pm 3 \sigma)$ on either side of the hypothetical peak centroid.

The MDC can be calculated by replacing $A$ in eq. (3) with the MDA from eq. (6) [18]. The half-lives and energies of the radionuclides of concern are listed in Table 1 . The MDCs for ${ }^{131} \mathrm{I}$ and ${ }^{137} \mathrm{Cs}$ were 5.4 and $4.3 \mu \mathrm{Bq} / \mathrm{m}^{3}$ respectively, as collection time, decay time, and acquisition time were all $24 \mathrm{~h}$ and the air volume was $10000 \mathrm{~m}^{3}$.

Produced by cosmic ray spallation in the stratosphere and upper troposphere, ${ }^{7} \mathrm{Be}$ can be used as an indicator of the overall quality of the aerosol sampling operations. ${ }^{7} \mathrm{Be}$ spontaneously attaches to atmospheric aerosols, and its activity in the atmosphere is mainly affected by the balance between solar radiation and aerosol deposition. Over intervals of days to weeks, the ${ }^{7} \mathrm{Be}$ concentrations at a given location are usually quite steady, and therefore, ${ }^{7} \mathrm{Be}$ can serve as an indicator of the reproducibility of a monitoring system, especially for long-term programs. The concentration of ${ }^{7} \mathrm{Be}$ ranged from 3.81 to $12.24 \mathrm{mBq} / \mathrm{m}^{3}$ during sampling period for the present study, and this is consistent with the activity of $2-12 \mathrm{mBq} / \mathrm{m}^{3}$ measured in Xi' an in 2002 by Chang et al. [22] The agreement in ${ }^{7}$ Be activities between the two programs indicate that the monitoring system worked well.

\subsection{Xenon monitoring}

Atmospheric xenon was collected with a sampler manufactured by the authors. The mechanics and operation of the sampler were as follows: air was compressed and passed through a column filled with molecular sieves to remove water vapor and carbon dioxide; xenon was absorbed in the first activated charcoal column at low temperature. The xenon was then desorbed at $200^{\circ} \mathrm{C}$ and passed to the second and third activated charcoal column where it was further purified by adsorption-desorption cycles in succession. The total xenon in $24 \mathrm{~h}$ samples was $>4 \mathrm{~mL}$ at standard temperature and pressure, and the effective air volume was approximate $50 \mathrm{~m}^{3}$. The ${ }^{133} \mathrm{Xe}$ activity was measured using a low-energy, planar, high-purity Ge, gamma-ray spectrometer and calculated from eq. (1). The detection efficiency of the spectrometer at $81 \mathrm{keV}$ was $50 \%$. The concentrations of stable xenon isotopes $\left({ }^{129} \mathrm{Xe}\right.$ and $\left.{ }^{132} \mathrm{Xe}\right)$ in the samples, measured using a quadrapole mass spectrometer [23], were used to calculate the sampling efficiency. The activity concentration of ${ }^{133} \mathrm{Xe}$ was calculated from eq. (7) which is based on the same principles as eq. (1).

$$
C_{\mathrm{X}}=\frac{A C_{0} P_{0} T}{V_{\mathrm{s}} C_{\mathrm{s}} P T_{0} K_{\mathrm{w}} K_{\mathrm{s}}},
$$

where $C_{\mathrm{X}}$ is activity concentration of ${ }^{133} \mathrm{Xe}, \mathrm{Bq} / \mathrm{m}^{3} ; A$ is activity of ${ }^{133} \mathrm{Xe}, \mathrm{Bq} ; C_{0}$ is atmospheric concentration of the stable xenon isotopes, $0.087 \times 10^{-6} \mathrm{v} / \mathrm{v}, P_{0}$ is standard pressure, $101.325 \mathrm{kPa} ; T$ is sample temperature, $\mathrm{K} ; V_{\mathrm{s}}$ is volume of sample container, $\mathrm{m}^{3} ; C_{\mathrm{s}}$ is concentration of stable xenon isotopes in the sample, v/v; $P$ is pressure inside sample container, $\mathrm{kPa} ; T_{0}$ is standard temperature, $273.15 \mathrm{~K}$; and $K_{\mathrm{w}}$ and $K_{\mathrm{s}}$ are as defined above. The MDA for ${ }^{133} \mathrm{Xe}$ can be calculated from eq. (6) and the MDC from eq. (7) by replacing $A$ by MDA. The MDC for ${ }^{133} \mathrm{Xe}$ was approximate $0.2 \mathrm{mBq} / \mathrm{m}^{3}$, as the collection times, times for preparing the samples and acquisition times were 24,3 , and $24 \mathrm{~h}$, respectively.

\section{Results and discussion}

\subsection{Concentrations of radionuclides}

A high concentration of ${ }^{131} \mathrm{I}$ was observed in the first particulate sample collected in the monitoring program, which was on March 23, 2011. Other radionuclides that are known to be released during accidents at nuclear power plants, including ${ }^{137} \mathrm{Cs},{ }^{134} \mathrm{Cs},{ }^{132} \mathrm{I}$ and ${ }^{132} \mathrm{Te}$, were observed in subsequent samples. It is worth noting that radionuclides with short half-lives are usually not detectable; the exception is ${ }^{137} \mathrm{Cs}$ which shows a very low background in atmosphere; for example, ${ }^{137} \mathrm{Cs}$ activity concentrations are typically $<0.001 \mathrm{mBq} / \mathrm{m}^{3}$ in Europe [4]. Time-series plots of the ${ }^{131} \mathrm{I}$, ${ }^{137} \mathrm{Cs}$ and ${ }^{134} \mathrm{Cs}$ activity concentrations at Xi' an are shown in Figure 1. The concentrations of other radionuclides whose concentrations quickly decreased below their MDCs are not shown. ${ }^{131}$ I showed two peak values one of 3.92 and the other $1.66 \mathrm{mBq} / \mathrm{m}^{3}$; these were on March 25 and April 5, respectively, but ${ }^{131} \mathrm{I}$ decreased exponentially after April 6 and reached its MDC on April 27.

The relationship between the concentrations of ${ }^{131} \mathrm{I}$ in the samples collected after April 6 and time was fitted by eq. (8):

$$
C_{t}(\mathrm{Y})=C_{0}(\mathrm{Y}) \exp [-k(\mathrm{Y}) t]
$$

where $C_{0}(\mathrm{Y})$ and $C_{t}(\mathrm{Y})$ are concentrations of radionuclide $\mathrm{Y}$ at the time 0 and time $t$, respectively, $\mathrm{Bq} / \mathrm{m}^{3}$; and $k(\mathrm{Y})$ is concentration-attenuation coefficient of radionuclide $\mathrm{Y}, \mathrm{d}^{-1}$.

\begin{tabular}{|c|c|c|c|c|c|c|c|}
\hline \multirow{2}{*}{ Property } & \multicolumn{7}{|c|}{ Radionuclides } \\
\hline & ${ }^{131} \mathrm{I}$ & ${ }^{132} \mathrm{Te}$ & ${ }^{132} \mathrm{I}$ & ${ }^{137} \mathrm{Cs}$ & ${ }^{134} \mathrm{Cs}$ & ${ }^{7} \mathrm{Be}$ & ${ }^{133} \mathrm{Xe}$ \\
\hline Half-life & $8.02 \mathrm{~d}$ & $76.8 \mathrm{~h}$ & $2.29 \mathrm{~h}$ & $30.1 \mathrm{a}$ & $2.07 \mathrm{a}$ & $53.3 \mathrm{~d}$ & $5.24 \mathrm{~d}$ \\
\hline Gamma energy (keV) & 364.5 & 228.2 & 667.7 & 661.6 & 604.7 & 477.6 & 81 \\
\hline
\end{tabular}

Table 1 Half-lives and gamma-ray energies for the radionuclides of interest 


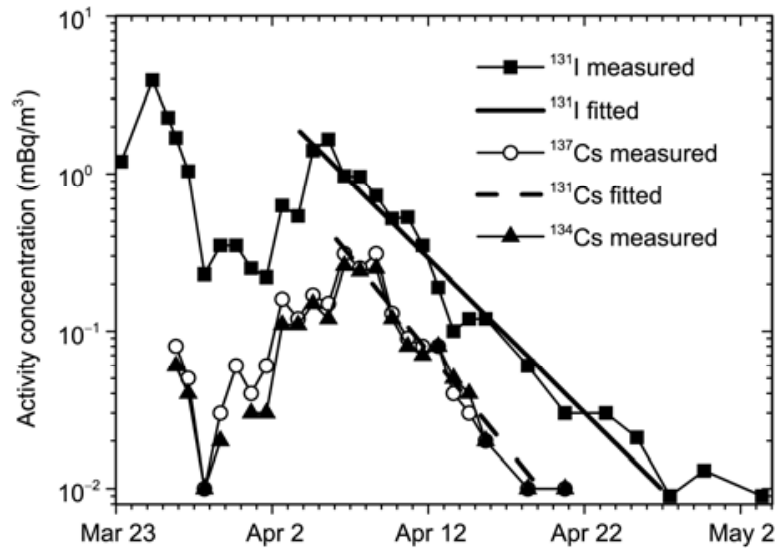

Figure 1 Time series of the activity concentrations of ${ }^{131} \mathrm{I},{ }^{134} \mathrm{Cs}$ and ${ }^{137} \mathrm{Cs}$. The lines were fitted with the data of samples collected after April 6.

The concentration-attenuation coefficient $k\left({ }^{131} \mathrm{I}\right)$ of 0.227 $\mathrm{d}^{-1}$ (squared correlation coefficient $\left(R^{2}\right)=0.9657$, Figure 1) calculated in this way is considerably larger than the decay constant for ${ }^{131} \mathrm{I}$ which is $0.0864 \mathrm{~d}^{-1}$, and this implies that levels of ${ }^{131}$ I were affected by gravitational settling and diffusive dilution in addition to radioactive decay. ${ }^{134} \mathrm{Cs}$ and ${ }^{137} \mathrm{Cs}$ showed maximum concentrations of 0.26 and 0.31 $\mathrm{mBq} / \mathrm{m}^{3}$, respectively, on April 6. The temporal trends in ${ }^{134} \mathrm{Cs}$ and ${ }^{137} \mathrm{Cs}$ were almost identical, and those trends were also similar to that of ${ }^{131} \mathrm{I}$; however, they lagged one day behind ${ }^{131} \mathrm{I}$. This may be due to the fact that a portion of the ${ }^{131} \mathrm{I}$ exists as gas in atmosphere, and therefore ${ }^{131} \mathrm{I}$ has a greater diffusivity than the particulate radionuclides. The concentration-attenuation coefficient for ${ }^{137} \mathrm{Cs}$ obtained by fitting the concentration data after April 6 was $k\left({ }^{137} \mathrm{Cs}\right)=$ $0.251 \mathrm{~d}^{-1}$ with $R^{2}=0.9061$, and this is much greater than the decay constant of $6.32 \times 10^{-5} \mathrm{~d}^{-1}$ and also greater than $k\left({ }^{131} \mathrm{I}\right)$. This finding shows that the ${ }^{137} \mathrm{Cs}$ activity decreased more quickly than ${ }^{131} \mathrm{I}$ at Xi' an. The reasons for this are likely complicated, but many iodine-containing compounds are volatile, and so a fraction of the deposited I can re-enter the atmosphere as a gas. In addition, iodine is likely to be concentrated on smaller aerosols than Cs, and so the gravitational settling term for the iodine-rich particles is also smaller than that for the larger Cs-containing particles. The mechanisms and processes responsible for the differences in the concentration-attenuation coefficients could be more thoroughly evaluated in future studies if information on the activities of the nuclides in deposited materials were collected.

The ${ }^{134} \mathrm{Cs} /{ }^{137} \mathrm{Cs}$ ratio can be used to discriminate between radioactive emissions from nuclear accidents versus those from nuclear explosions [18]. In a nuclear reactor, ${ }^{133} \mathrm{Xe}$ decays to the stable nuclide ${ }^{133} \mathrm{Cs}$ which can be activated to ${ }^{134} \mathrm{Cs}$, as follows:

$$
{ }^{133} \mathrm{Xe} \stackrel{\beta}{\longrightarrow}{ }^{133} \mathrm{Cs} \stackrel{n, \gamma}{\longrightarrow}{ }^{134} \mathrm{Cs}
$$

The net result of this is that the activity of ${ }^{134} \mathrm{Cs}$ in a nu- clear reactor can grow to match to that of ${ }^{137} \mathrm{Cs}$, but in contrast, little ${ }^{134} \mathrm{Cs}$ is produced in a nuclear explosion, and so with the presence of ${ }^{134} \mathrm{Cs}$ alone or a high ${ }^{134} \mathrm{Cs} /{ }^{137} \mathrm{Cs}$ ratio is indicative of material from a nuclear reactor. The ${ }^{134} \mathrm{Cs} /$ ${ }^{137} \mathrm{Cs}$ ratio observed after the Chernobyl nuclear accident was reported about 0.58 [18] and a ratio of 0.88 was observed during our monitoring in Xi' an; both values are consistent with releases from nuclear reactors.

A time-series plot of the ${ }^{133} \mathrm{Xe}$ concentrations from March 27 to June 10 is shown in Figure 2. The maximum ${ }^{133} \mathrm{Xe}$ concentration $\left(5.5 \mathrm{~Bq} / \mathrm{m}^{3}\right)$ occurred on March 27, and two subsequent peaks in ${ }^{133} \mathrm{Xe}\left(1.0\right.$ and $\left.0.88 \mathrm{~Bq} / \mathrm{m}^{3}\right)$ were observed on March 30 and April 5, respectively. The final peak occurred on the same day when the peak in ${ }^{131} \mathrm{I}$ was observed. The concentration of ${ }^{133} \mathrm{Xe}$ decreased exponentially after April 5. The fitted concentration-attenuation coefficient $k\left({ }^{133} \mathrm{Xe}\right)$ was $0.130 \mathrm{~d}^{-1}$, and this is nearly the same as its radioactive decay constant, $0.132 \mathrm{~d}^{-1}$. Therefore, the decrease $i{ }^{133} \mathrm{Xe}$ observed in our study can be attributed almost solely to radioactive decay. It is likely that little additional ${ }^{133} \mathrm{Xe}$ was released into atmosphere after April 5, and at that point, the ${ }^{133} \mathrm{Xe}$ might have been widely dispersed throughout the atmosphere. As a result, further diffusive dilution in the atmosphere showed little or no effect on the concentration of ${ }^{133} \mathrm{Xe}$.

Based on the observed radionuclide concentrations at Xi'an, it can be concluded that the additional annual effective dose attributable to the emissions from Fukushima was much lower than the public annual effective dose caused by natural radiation, according to the standards established by the Chinese government [24]. This implies that the atmospheric radionuclides from the stricken reactor had little or no impact on the environmental radiation levels in Xi' an during the monitoring period even though their concentrations were much higher than the backgrounds on some days.

\subsection{Comparison with the chernobyl nuclear accident}

Massive amounts of radionuclides were released into

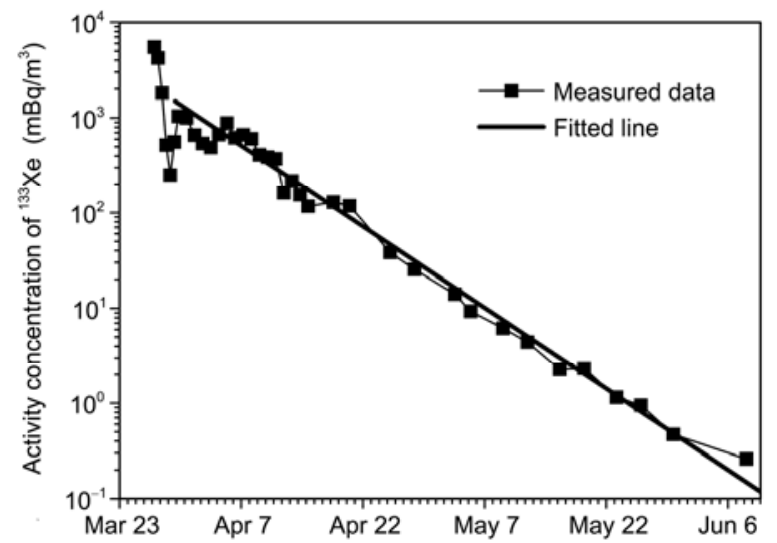

Figure 2 Time series of ${ }^{133} \mathrm{Xe}$ concentration. The line was fitted using the data of samples collected after April 6. 
atmosphere as a result of the Chernobyl accident, as shown in Table 2, and their imprint on global environmental radioactivity was of such a great magnitude that research on their impact has continued for decades. The quantities of the main radionuclides released by the Fukushima accident were comparable to those from Chernobyl according to the estimates shown in Table 2. Comparing the monitoring results in Xi'an in 2011 after the Fukushima accident with those in 1986 after the Chernobyl accident [25], one finds that (1) only volatile radionuclides such as ${ }^{131} \mathrm{I},{ }^{134} \mathrm{Cs}$ and ${ }^{137} \mathrm{Cs}$ were observed in 2011 but both volatile radionuclides and other radionuclides such as ${ }^{143} \mathrm{Ce},{ }^{140} \mathrm{Ba}$ and ${ }^{140} \mathrm{La}$ were observed in 1986, and (2) the concentrations of radionuclides in 2011 were 10 to 100 times lower than those in 1986. Similar results were also observed at other locations; for example, the concentrations of ${ }^{137} \mathrm{Cs}$ in Europe in 2011 were 100 to 1000 times lower than those in 1986 [4].

The lower radionuclide concentrations observed in Xi' an and other sites in 2011 compared with 1986 likely resulted from differences in the way the accidents unfolded at the two reactors as much or more than the quantities of radionuclides released. At Chernobyl, the reactor exploded prior to the melt down of the nuclear fuel and the burning of the graphite control rods. It has been estimated that of all nuclear materials produced at Chernobyl, $100 \%$ of the gaseous fission products, such as ${ }^{133} \mathrm{Xe}$, were released, $50 \%-60 \%$ of the ${ }^{131} \mathrm{I}$ was released, $20 \%-40 \%$ of the ${ }^{134} \mathrm{Cs}$ and ${ }^{137} \mathrm{Cs}$ were released, and approximate $3.5 \%$ of the refractory fission products, such as ${ }^{95} \mathrm{Zr},{ }^{95} \mathrm{Nb}$ and ${ }^{144} \mathrm{Ce}$ as well as transuranic nuclides were released [26]. In comparison, the hydrogen explosions and the fire in the spent fuel pool at the Fukushima reactor resulted in temperatures that were much lower than those at the Chernobyl, and as a result, it was primarily the volatile radionuclides that were released there. Location also played role in the distribution of radionuclides: Chernobyl lies in the central part of the Eurasia and much of the former USSR and Europe were heavily contaminated [26]. Fukushima, on the other hand, lies along the western rim of the Pacific, and the winds were mainly westerly during the accident: consequently, most of released radionuclides were transported over the Pacific before eventually reaching land [13].

\subsection{Comparison with the results from other locations}

(1) Japan (see footnote 1 on page 1586). According to the

Table 2 Comparison of estimated activities of radionuclides $(\mathrm{Bq})$ released at Fukushima versus those from Chernobyl

\begin{tabular}{ccc}
\hline Radionuclides & Fukushima & Chernobyl [26] \\
\hline${ }^{131} \mathrm{I}$ & $1.5 \times 10^{17}[12]$ & $1.76 \times 10^{18}$ \\
${ }^{134} \mathrm{Cs}$ & - & $5.4 \times 10^{16}$ \\
${ }^{137} \mathrm{Cs}$ & $1.3 \times 10^{16}[12], 3.58 \times 10^{16}[13]$ & $8.5 \times 10^{16}$ \\
${ }^{133} \mathrm{Xe}$ & $1.67 \times 10^{19}[13]$ & $6.5 \times 10^{18}$ \\
\hline
\end{tabular}

results reported for RN38 (Takasaki, $200 \mathrm{~km}$ southwest of Fukushima), ${ }^{134} \mathrm{Cs},{ }^{136} \mathrm{Cs},{ }^{137} \mathrm{Cs},{ }^{131} \mathrm{I},{ }^{132} \mathrm{I},{ }^{133} \mathrm{I},{ }^{132} \mathrm{Te},{ }^{136 \mathrm{~m}} \mathrm{Ba}$ and ${ }^{133} \mathrm{Xe}$ were observed on March 12, and the concentrations of ${ }^{131} \mathrm{I}$ and ${ }^{137} \mathrm{Cs}$ peaked at 15 and $5.6 \mathrm{~Bq} / \mathrm{m}^{3}$, respectively, on March 16. The maximum concentration of ${ }^{133} \mathrm{Xe}$ exceeded $100 \mathrm{~Bq} / \mathrm{m}^{3}$. Peaks in ${ }^{131} \mathrm{I}$ and ${ }^{137} \mathrm{Cs}$ occurred several times in March, then the concentrations held relatively steady in April, and decreased to about $1 \mathrm{mBq} / \mathrm{m}^{3}$ by the end of May.

(2) North America. The United States [1,27] was the first country outside of Japan where radionuclides released during the Fukushima accident were observed. Excess radioactivity was first detected on March 15, and the observed radionuclides were same as those in Japan. The concentrations of ${ }^{131} \mathrm{I}$ and ${ }^{133} \mathrm{Xe}$ peaked at $30 \mathrm{mBq} / \mathrm{m}^{3}$ and $17 \mathrm{~Bq} / \mathrm{m}^{3}$, respectively. The activity concentrations of ${ }^{131} \mathrm{I}$ were steady during March and then showed a gradual decrease. The situation in Canada [2,3] was essentially the same as in the United States.

(3) Europe [4]. The observed radionuclides included ${ }^{131} \mathrm{I},{ }^{134} \mathrm{Cs},{ }^{137} \mathrm{Cs},{ }^{132} \mathrm{Te}$ and ${ }^{132} \mathrm{I}$. The ${ }^{131} \mathrm{I}$ activity concentrations showed two peaks, the first appeared between March 26 to 28 at various countries, and the second occurred between April 3 and 5. The peak concentrations of ${ }^{131} \mathrm{I}$ were $1-6 \mathrm{mBq} / \mathrm{m}^{3}$.

(4) Other Asian countries. ${ }^{131} \mathrm{I},{ }^{134} \mathrm{Cs}$ and ${ }^{137} \mathrm{Cs}$ were observed in Vietnam beginning on March 27 [9]. The maximum power plant nuclide concentrations appeared on April 10, with ${ }^{131}$ I reaching $0.93 \mathrm{mBq} / \mathrm{m}^{3}$ and ${ }^{137} \mathrm{Cs}$ peaking at $0.036 \mathrm{mBq} / \mathrm{m}^{3}$. The radioactive plume was detected in Korea on March 28, and there ${ }^{131} \mathrm{I}$ peaked at $3.12 \mathrm{mBq} / \mathrm{m}^{3}$ on April 6 [8]. Backward trajectory analysis showed that the air masses passed over Beijing prior to arriving in Korea.

Comparing the above results, one sees that the concentrations in Xi' an were much lower than those in Japan or the United States, but similar to those in Europe. The sequence of arrival was as follows: Japan, North America, China and Europe. The arrival time in Xi' an was March 25 and that preceded the detection of the power plant radionuclides in Europe by three to four days. That is, the air that arrived at Xi'an containing the Fukushima nuclides evidently did not first pass over Europe. The transport pathways were analyzed to determine how this was possible.

\subsection{Pathway of the radionuclides arriving at Xi'an}

The first radionuclide releases from Fukushima occurred on March 12. The first plume containing ${ }^{131} \mathrm{I}$ was observed in Xi' an on March 25, thirteen days after initial release. Xi' an lies in the central part of China, approximate $2800 \mathrm{~km}$ west of Fukushima, and it is instructive to investigate how the radionuclides reached $\mathrm{Xi}$ 'an, especially the pathways they followed. The transport of radionuclides to Europe was analyzed by Lozano et al. [28] who used the HYSPLIT (the Hybrid Single Particle Lagrangian Integrated Trajectory), 

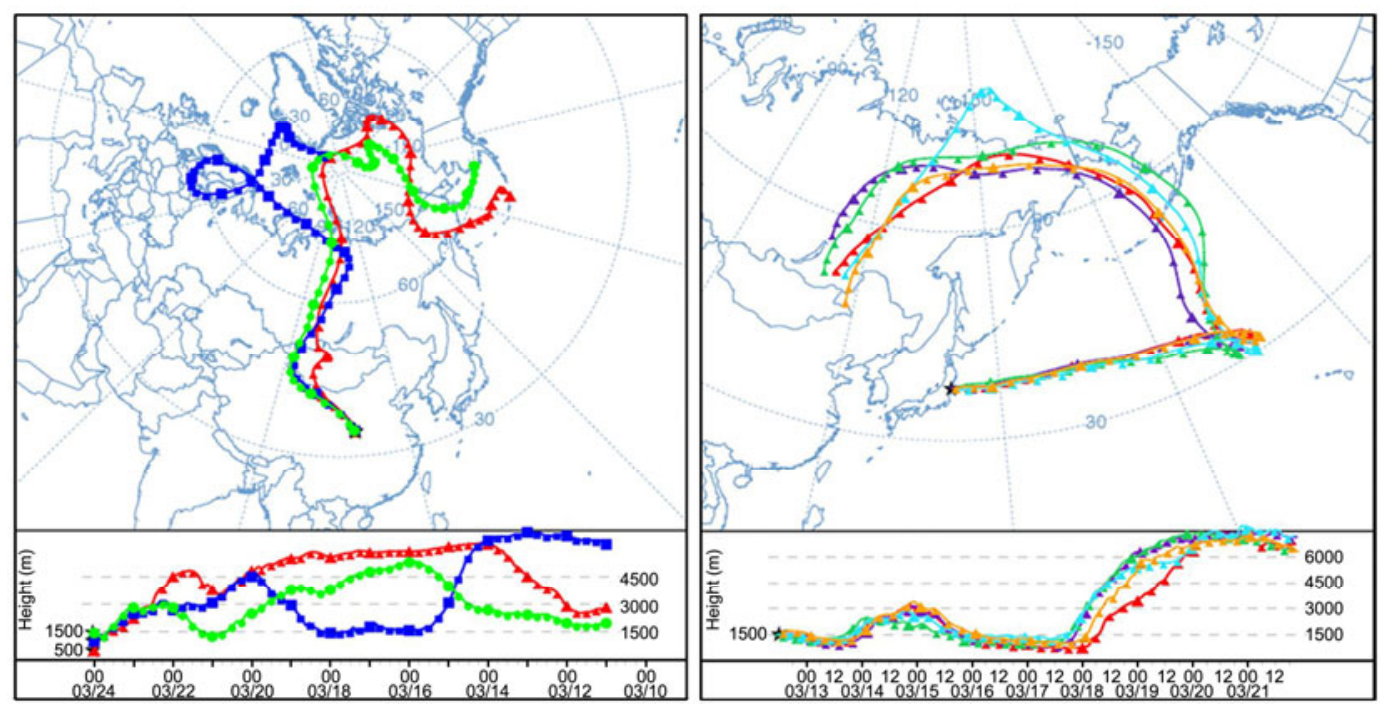

Figure 3 Trajectories of air masses from Fukushima to Xi'an by HYSPLIT. (a) Backward trajectories ending at 0100 UTC Mar 24, Xi'an; (b) forward trajectories starting at 1000-1400 UTC Mar 12, Fukushima.

but Asian countries were not included in their analysis. Qiao et al. [14] predicted the dispersion of the released radionuclides using the CCSM3 model, but that analysis was based on the proportions of the maximum concentrations, and those numbers are difficult to compare with the activity concentrations from our study. Kuang et al. [29] analyzed the radionuclide transport pathways and suggested that the air containing the Fukushima radionuclides split into three branches after reaching the Pacific, and as a result the contaminants moved northward, eastward, and southward. The northward flowing branch would have arrived in eastern and northeast China after crossing Russia. The southward flow would have turned to the southwest to arrive at Hainan Island, China after passing the Philippines. If those pathways were accurate representations of the flow, the released radionuclides would have entered China by both the northern and southern pathways.

As part of our study, both forward trajectories from $\mathrm{Fu}-$ kushima as well as backward trajectories arriving at Xi'an were calculated using the HYSPLIT model. The results showed that the westerly winds controlled the transport at altitudes higher than $3000 \mathrm{~m}$, but a transient anticyclone was encountered at an altitude of about $1500 \mathrm{~m}$ (Figure 3). The flow associated with anticyclone made it possible for air mass containing the Fukushima radionuclides to arrive at China without first crossing over North America or Europe, and this explains how the radionuclides arrived in China at the same time as in Europe or even earlier. Taking the arrival times at the various locations into account, it appears that some of the radioactivity apparently moved northward and some southward after the flow over the Pacific diverged, but then both plumes turned westward before arriving in northern and southern parts of the East Asia. This westward turn in the flow explains how the radioactivity released from Fukushima arrived in Xi' an before reaching Europe.

\section{Conclusions}

Atmospheric radionuclide monitoring was conducted in Xi' an for three months, starting $12 \mathrm{~d}$ after the Fukushima accident, and time-series of the ${ }^{131} \mathrm{I},{ }^{134} \mathrm{Cs},{ }^{137} \mathrm{Cs}$ and ${ }^{133} \mathrm{Xe}$ concentrations were obtained. The additional annual effective dose due to the observed activity was much lower than the public annual effective dose, and by that measure, the environmental radiation level in Xi' an was not significantly affected.

Analysis of the atmospheric transport pathways showed that the movements of the released radionuclides were initially controlled by the westerly winds, but they were later affected by an anticyclone that developed over the Pacific Ocean. Divergence in the flow, as well as extended time interval over which the radioactivity was released, complicates the interpretation of transport. Nonetheless, the information obtained by rapidly implementing a program for monitoring the radioactivity released from Fukushima has provided insights not only into the transport of the radionuclides but also the pathways that can be followed by other constituents of the atmosphere.

1 Diazleon J, Jaffe D A, Kaspar J, et al. Arrival time and magnitude of airborne fission products from the Fukushima, Japan, reactor incident as measured in Seattle, WA, USA. J Environ Radioact, 2011, 102: 1032-1038

2 Sinclair L E, Seywerd H C J, Fortin R, et al. Aerial measurement of radioxenon concentration off the west coast of Vancouver Island following the Fukushima reactor accident. J Environ Radioact, 2011, 102: 1018-1023

3 Zhang W, Bean M, Benotto M, et al. Development of a new aerosol monitoring system and its application in Fukushima nuclear accident related aerosol radioactivity measurement at the CTBT radionuclide station in Sidney of Canada. J Environ Radioact, 2011, 102: 1065-1069

4 Masson O, Baeza A, Bieringer J, et al. Tracking of airborne radionu- 
clides from the damaged Fukushima Dai-ichi nuclear reactors by European networks. Environ Sci Tech, 2011, 45: 7670-7677

5 Manolopoulou M, Vagena E, Stoulos S, et al. Radioiodine and radiocesium in Thessaloniki, Northern Greece due to the Fukushima nuclear accident. J Environ Radioact, 2011, 102: 796-797

6 Pittauerová D, Hettwig B, Fischer H W. Fukushima fallout in Northwest German environmental media. J Environ Radioact, 2011, 102: $877-880$

7 Bolsunovsky A, Dementyev D. Evidence of the radioactive fallout in the center of Asia (Russia) following the Fukushima nuclear accident. J Environ Radioact, 2011, 102: 1062-1064

8 Kim C, Byun J, Chae J, et al. Radiological impact in Korea following the Fukushima nuclear accident. J Environ Radioact, 2012, 111: 70-82

9 Long N Q, Truong Y, Hien P D, et al. Atmospheric radionuclides from the Fukushima Dai-ichi nuclear reactor accident observed in Vietnam. J Environ Radioact, 2012, 111: 53-58

10 Bowyer T W, Biegalski S R, Cooper M, et al. Elevated radioxenon detected remotely following the Fukushima nuclear accident. J Environ Radioact, 2011, 102: 681-687

11 Medici F. The IMS radionuclide network of the CTBT. Radiat Phys Chem, 2001, 61: 689-690

12 Chino M, Hiromasa N, Haruyasu N, et al. Preliminary estimation of release amounts of ${ }^{131} \mathrm{I}$ and ${ }^{137} \mathrm{Cs}$ accidentally discharged from the Fukushima Daiichi nuclear power plant into the atmosphere. J Nucl Sci Tech, 2011, 48: 1129-1134

13 Stohl A, Seibert P, Wotawa G, et al. Xenon-133 and caesium-137 releases into the atmosphere from the Fukushima Dai-ichi nuclear power plant: Determination of the source term, atmospheric dispersion, and deposition. Atmos Chem Phys Discuss, 2011, 11: 28319-28394

14 Qiao F, Wang G, Zhao W, et al. Predicting the spread of nuclear radiation from the damaged Fukushima nuclear power plant. Chin Sci Bull, 2011, 56: 1890-1896

15 Wang H, Wang X, Huang S, et al. Fukushima Dai-ichi NPP accident source term estimation and methods comparison (in Chinese). Nucl Safety, 2011, 2: 14-19

16 Zhou C, Zhang Q, Jiang Y, et al. Monitoring and evaluation of radioactive aerosols in the Nanjing air during Japan's nuclear leakage (in Chinese). Admin Tech Environ Monitor, 2011, 23: 43-45
17 Preparatory Commission for the Comprehensive Nuclear-Test-Ban Treaty Organization. Certification of IMS Radionuclide Stations (with Guidelines for Station Installation), 1999

18 Zhang L, Zhu F. Radionuclides Monitoring Techniques for Nuclear Tests (in Chinese). Beijing: Chemical Industrial Press, 2006. 72-74

19 Chang Y, Liu L, Wang S, et al. Development of PMS-800 atmospheric particulate sampler (in Chinese). Radia Prot, 2011, 31: 39-42

20 Wu Y, Wang X, Liu L, et al. Performance measurement at high filtration velocity for sampling filter (in Chinese). Radia Prot, 2009, 29: 13-17

21 Wu Z, Zhao G, Lu F. Experimental Methods for Nuclear Physics (in Chinese). Beijing: Atomic Energy Press, 1997. 272

22 Chang Y, Wang X, Wang S, et al. Radionuclides monitoring in atmospheric aerosol samples in Xi' an (in Chinese). Nucl Tech, 2008, 31: 796-800

23 Zhang Z, Goetz A, Wei G, et al. A bench quadrupole mass spectrometer for accurate analysis of trace noble gas (in Chinese). J Chin Mass Spec Soc, 2004, 25: S203-S204

24 General Administration of Quality Supervision, Inspection and Quarantine of the People's Republic of China. Basic Standards for Protection Against Ionizing Radiation and for the Safety of Radiation Sources. GB18871-2002. 2002

25 Pang J, Zheng G, Wang L, et al. Environmental impact of Chernobyl accident on Xi' an area and health evaluation (in Chinese). Nucl Tech, 1989, 12: 713-719

26 Nuclear Energy Agency, the Organisation for Economic Co-operation and Development. Chernobyl: Assessment of Radiological and Health Impacts - 2002 Update of Chernobyl: Ten Years on. Paris: OECD, 2002

27 Biegalski S R, Bowyer T W, Eslinger P W, et al. Analysis of data from sensitive U.S. monitoring stations for the Fukushima Dai-ichi nuclear reactor accident. J Environ Radioact, 2011, 114: 15-21

28 Lozano R L, Hernández-Ceballos M A, Adame J A, et al. Radioactive impact of Fukushima accident on the Iberian Peninsula: Evolution and plume previous pathway. Environ Int, 2011, 37: 1259-1264

29 Kuang F, Wang S, Liu L, et al. The simulation of radionuclide dispersion of Fukushima Daiichi NPP accident (in Chinese). Atom Energ Sci Tech, 2012, 46: 1533-1536

Open Access This article is distributed under the terms of the Creative Commons Attribution License which permits any use, distribution, and reproduction in any medium, provided the original author(s) and source are credited. 